\title{
High-contrast slab waveguide fabrication in KY(WO4)2 by swift heavy ion irradiation
}

Frentrop, R., Tormo-Márquez, V., Olivares, J., GarcíaBlanco, S.

R. N. Frentrop, V. Tormo-Márquez, J. Olivares, S. M. García-Blanco, "Highcontrast slab waveguide fabrication in KY(WO4)2 by swift heavy ion irradiation," Proc. SPIE 10535, Integrated Optics: Devices, Materials, and Technologies XXII, 105350 (23 February 2018); doi: 10.1117/12.2290045

SPIE. Event: SPIE OPTO, 2018, San Francisco, California, United States 


\title{
High-contrast slab waveguide fabrication in $\mathrm{KY}\left(\mathrm{WO}_{4}\right)_{2}$ by swift heavy ion irradiation
}

\author{
R.N. Frentrop ${ }^{*}$, a, V. Tormo-Marquez ${ }^{\text {b }}$ J. Olivares ${ }^{\text {b,c }}$, S.M. García-Blanco ${ }^{\text {a }}$ \\ ${ }^{a}$ Optical Sciences Group, MESA+ Institute for Nanotechnology, University of Twente, P.O. Box \\ 217, 7500 AE Enschede, The Netherlands; ${ }^{b}$ Centro de Micro-Análisis de Materiales, Universidad \\ Autónoma de Madrid, E-28049-Madrid, Spain; ' Instituto de Óptica "Daza de Valdés", Consejo \\ Superior de Investigaciones Científicas (CSIC), Calle Serrano 121, E-28006-Madrid, Spain \\ *r.n.frentrop@utwente.nl; phone+31 53489 8975; os.tnw.utwente.nl
}

\begin{abstract}
$\mathrm{KY}\left(\mathrm{WO}_{4}\right)_{2}$ and other materials of the double tungstate crystal family have been used for decades in active optical applications because of their relatively high refractive index $(\mathrm{n} \approx 2-2.04 @ 1550 \mathrm{~nm})$, high transparency window $(0.3-$ $5 \mu \mathrm{m})$, excellent gain characteristics when doped with rare-earth ions and reasonably high thermal conductivity $\left(\sim 3.3 \mathrm{Wm}^{-1} \mathrm{~K}^{-1}\right)$. Low-contrast $(\Delta \mathrm{n}<0.02)$ on-chip amplifiers and lasers in this material with good performance have been shown in recent years. Higher refractive index contrast can further improve this performance, and allow easier integration with other integrated optics platforms due to their smaller footprint. Because double tungstate materials cannot be directly grown on many prospected substrates, other methods to fabricate optical waveguides with a thickness of 1-2 $\mu \mathrm{m}$ need to be investigated. In this work, swift heavy ion irradiation has been used to produce a planar waveguide by introducing a buried layer of lower refractive index in the $\mathrm{KY}\left(\mathrm{WO}_{4}\right)_{2}$ at a depth of $\sim 2.5 \mu \mathrm{m}$. After the irradiation, an annealing step was introduced to reduce the scattering losses. The refractive index profile, effective refractive indices and absorption spectra of the planar waveguides have been investigated for several annealing temperatures, and end-facet free-space coupling of $1550 \mathrm{~nm}$ has been used to measure the losses. For a fluence of $3 \cdot 10^{14} \mathrm{ion} / \mathrm{cm}^{2}$ of $9 \mathrm{MeV} \mathrm{C}$ ions, propagation losses $<1.5 \mathrm{~dB} / \mathrm{cm}$ have been demonstrated at $1550 \mathrm{~nm}$ after an annealing step at $350^{\circ} \mathrm{C}$.
\end{abstract}

Keywords: integrated optics, ion irradiation, swift heavy ion, characterization, double tungstate, high index contrast

\section{INTRODUCTION}

Crystalline materials from the monoclinic potassium double tungstate family (i.e., $\mathrm{KY}\left(\mathrm{WO}_{4}\right)_{2}, \mathrm{KGd}\left(\mathrm{WO}_{4}\right)_{2}$, in short $\left.\mathrm{KRE}\left(\mathrm{WO}_{4}\right)_{2}\right)$, where RE refers to "rare-earth") have been used for decades as active materials for high-power ultra-short pulsed lasers [1]-[3], thin-disk amplifiers [4] and lasers [5], and Raman lasers [6]-[8]. They have gained interest over the last two decades as active materials for integrated photonics, thanks to their high refractive index $(\mathrm{n}=2-2.04 @ 1550 \mathrm{~nm}$ [9]), reasonably large thermal conductivity $\left(\sim 3.3 \mathrm{Wm}^{-1} \mathrm{~K}^{-1}\right)$, long inter-ionic distances $(<\mathrm{d}>\approx 0.5 \mathrm{~nm}[10])$, large transition cross-sections for rare-earth ions [11] and high nonlinear optical properties [12]. Recently, rare-earth ion doped, active optical waveguides have been demonstrated for the fabrication of on-chip amplifiers [13] and lasers [14]. These waveguides were grown using liquid phase epitaxy (LPE) [15] on an undoped potassium yttrium double tungstate

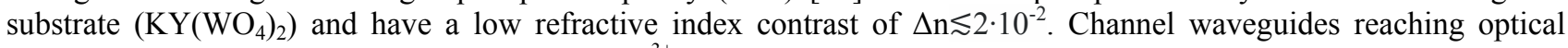
internal gain up to $\sim 1000 \mathrm{~dB} / \mathrm{cm}$ for $47.5 \mathrm{at} \% \mathrm{Yb}^{3+}$ doped $\mathrm{KY}\left(\mathrm{WO}_{4}\right)_{2}$ [13] and a lasing output power of up to $1.6 \mathrm{Win} 8$ at $\% \mathrm{Tm}^{3+}$ doped $\mathrm{KY}\left(\mathrm{WO}_{4}\right)_{2}$ at $1840 \mathrm{~nm}$ [14] were demonstrated. High-index contrast waveguides are expected to improve on this performance even further, because of the increased field intensity inside the waveguide, which reduces the required pump power. However, fabrication of thin single crystal optical quality layers of KREW on substrate materials with low refractive index is not possible using LPE because of lattice mismatch. Alternative methods need to be investigated. A lapping and polishing approach has been shown to produce thin layers [16]. This method has the difficulty of accurately controlling the thickness of the final KREW layer. Both laser writing [17] and ion irradiation with light [18], [19] and heavy [20]-[22] ions enable the fabrication of thin optically guiding layers in various materials, including members of the KREW family. In ion irradiated slab waveguides, the depth of the core is accurately determined by the energy of the impinging ions. In this work, heavy ion irradiation has been explored as a method to fabricate high-index contrast slab waveguides in $\mathrm{KY}\left(\mathrm{WO}_{4}\right)_{2}$ with relatively low optical losses. 


\subsection{Ion irradiation}

The optically guiding layer at the surface of a $\mathrm{KY}\left(\mathrm{WO}_{4}\right)_{2}$ crystal has been produced by carbon (swift) heavy ion irradiation perpendicular to the a-c crystal plane (Figure 1(b)). The obtained refractive index profile is a direct result of the damage caused by a combination of the ionizing effect, and ballistic interactions of the high-energy charged particles (e.g. ions) with the target material (i.e., $\mathrm{KY}\left(\mathrm{WO}_{4}\right)_{2}$ ), as shown in Figure 1(a). The ionization induced damage (i.e., the electronic damage) depends on the amount of energy deposited as a function of depth in the material. It can be described by the thermal spike model [23]. Accumulation of damage in the crystalline structure can result in full amorphization. This occurs when the amount of deposited energy is above the amorphization threshold. Besides the electronic damage, additional damage is created by ballistic interaction of the ions with the target material at the end of the ion range. This damage is called nuclear damage. The damaged material has a different - and in the case of $\mathrm{KY}\left(\mathrm{WO}_{4}\right)_{2}$ lower refractive index than the original crystalline material. Swift heavy ions have been chosen for this work because of the dominant electronic damage, the relatively fast damage accumulation compared to light ions, and the large tunability of the refractive index profile by varying the ion type, energy and fluence.. The SRIM-2013 software [24] and previous knowledge in comparable materials [20] was used to get an estimate of ion type, energy and fluence that would result in a step-like refractive index profile supporting single mode propagation around $1550 \mathrm{~nm}$ while limiting the damage at the surface. Fine tuning of the parameters was performed experimentally. This resulted in the choice for $9 \mathrm{MeV}$ carbon ions with a fluence of $3 \cdot 10^{14}$ ions $/ \mathrm{cm}^{2}$.
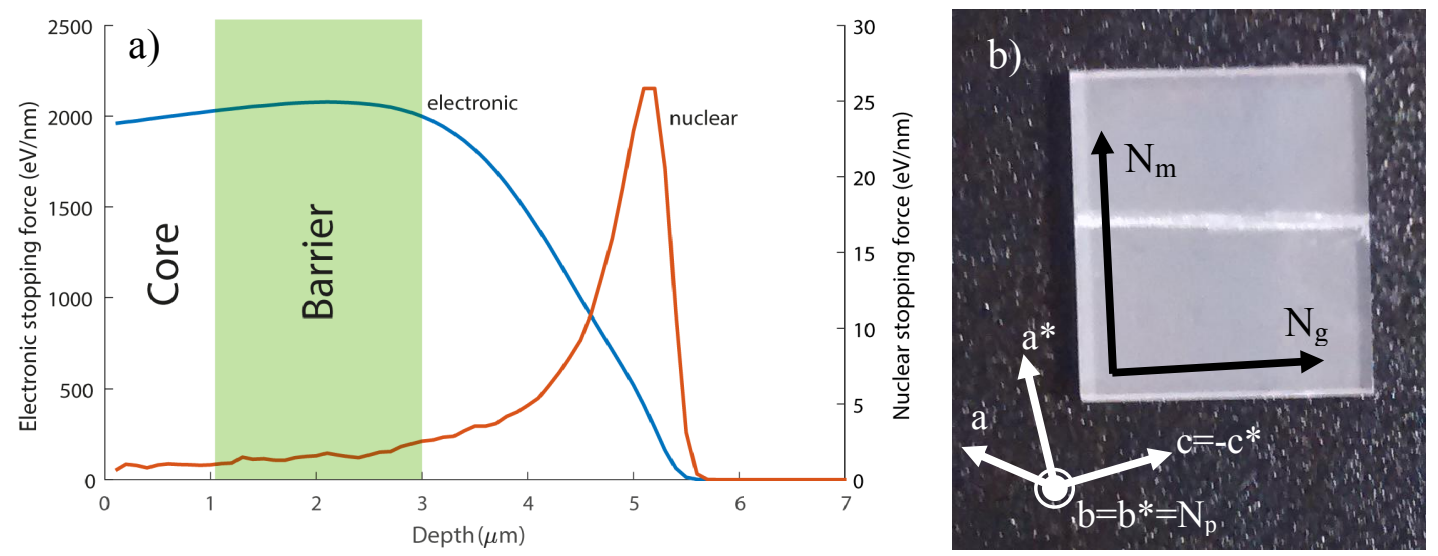

Figure 1. a) the electronic and nuclear energy loss distributions in $\mathrm{KY}\left(\mathrm{WO}_{4}\right)_{2}$ calculated by SRIM for 9 MeV carbon ions using 100.000 ions. The corresponding damage induces a refractive index contrast between a buried layer (barrier) of maximum damage and the surrounding material, which results in a higher index surface layer (core) that can be used as an optical slab waveguide. b) one of the investigated samples. The axes along which the sample has been cut are identified by the black markers. The crystalline axes for both the $C 2 / m(a, b, c)$ and $I 2 / c\left(a^{*}, b^{*}, c^{*}\right)$ space groups are also indicated.

\section{EXPERIMENTAL METHODS}

The KY $\left(\mathrm{WO}_{4}\right)_{2}$ crystals with dimensions $10 \times 10 \times 1 \mathrm{~mm}^{3}(a \times b \times c)$ were obtained from Altechna (LT) with one $a-c$ plane (with $b$-axis pointing in) polished to optical quality (RMS $\sim 1 \mathrm{~nm}$ ). Ion irradiation was performed in the $5 \mathrm{MV}$ electrostatic tandem accelerator of the Centro de Micro-Análisis de Materiales (CMAM) of the Universidad Autónoma de Madrid (UAM) in Spain. The samples were attached to a sample holder with double-sided copper tape and tilted at $5^{\circ}$ during irradiation to avoid ion channeling. A scratch was made on the sample with a diamond pencil to avoid cracking of the sample due to stress during the irradiation. The ion beam area was set much larger than the sample to ensure an even ion fluence over the whole sample. The ion current was kept relatively low to avoid heating the sample above $100^{\circ} \mathrm{C}$. After irradiation, one of the $a-b$ end-facets was polished using a Logitech MP5 (UK) polishing machine and a $40 \mathrm{~nm}$ $\mathrm{SiO}_{2}$ polishing suspension. A polishing wax was used to fix the sample for polishing and avoid rounding effects, which required heating of the sample to $100^{\circ} \mathrm{C}$. The sample was annealed to remove color centers and reduce point defects in the material, which is an important step to reduce optical propagation losses. Several annealing temperatures have been explored to determine the lowest possible propagation losses. 
Optical transmission though the irradiated crystal, perpendicular to the a-c surface, was measured and compared with the transmission of an unirradiated crystal to check whether the irradiation damage (e.g. color centers) or the presence of carbon affect the transparency of the material. These measurements were done in an Avantes spectrometer equipped with a white light source with an effective wavelength range of 400-750 nm. This range covers any significant absorption by carbon [25] and color center formation.

The refractive index profile caused by the irradation was measured using a micro-reflectivity setup [26]. A $635 \mathrm{~nm}$ diode laser source was used with a 100x objective and a Piezosystem Jena PXY 80 D12 closed-loop piezo actuator controlled by LabVIEW using a USB-6212 DAQ-card. The piezo actuator has an accuracy of $16 \mathrm{~nm}$, but the setup is diffraction limited to a spatial resolution of $\sim 300 \mathrm{~nm}$. The $100 \mathrm{x}$ objective has a NA=0.9, and was underfilled to avoid underestimation of the $\Delta \mathrm{n}$. An optical isolator was omitted as no intensity fluctuations were observed as a result of backreflections. The reflection intensity as function of position can be used to calculate the refractive index profile [19]

$$
n(z)=n_{r e f}-\frac{n_{r e f}^{2}-1}{4} \frac{R_{r e f}-R(z)}{R_{r e f}}
$$

With $n_{r e f}$ the refractive index of the unirradiated crystal matching the laser polarization, $R_{r e f}$ the reference reflection intensity of the unirradiated material, and $n(z)$ and $R(z)$ the refractive index and reflection intensity of the irradiated material as function of position, respectively. This technique requires the inspected surface to be optically flat.

Characterization of the slab waveguides was also performed by measuring the propagation constants of the supported slab modes. This was done using a Metricon 2010/M prism coupling system with laser sources of $632.8 \mathrm{~nm}, 830 \mathrm{~nm}$, $1300 \mathrm{~nm}$ and $1550 \mathrm{~nm}$, and a rutile coupling prism. The setup has an expected refractive index accuracy of $\sim 1 \cdot 10^{-4}$. The refractive index profile measured by micro-reflectivity has been used for mode calculations in Lumerical MODE solutions to compare the results of these two measurement methods.

Transmission loss measurements were performed by end-facet coupling into the slab waveguide with a 100x objective and a cylindrical lens to match the incident field to the slab mode of the waveguide. The scattered light was recorded with a camera situated perpendicular to the a-c crystal plane. Using the reference intensity $I(0)$ and the intensity at any point $x, I(z)$, the transmission at any point $x$ is given by

$$
\eta(x)=\frac{I(x)}{I(0)}=e^{-\alpha x}
$$

This results in an optical loss in $\mathrm{dB} / \mathrm{cm}$ of

$$
L=\frac{-10 \log _{10} e^{-\alpha x}}{x} \approx 4.34 \alpha
$$

where $\alpha$ is the fitted exponent of the scattered light intensity recorded by the camera [27]. The influence of background light on the measurement was minimized by subtracting the intensity profile of a non-illuminated part of the sample from the profile of the guided light. The small sample size and intrinsic limitation of this measurement method with respect to the noise pattern of the intensity generally limits the detection of this method to transmission losses of $>1 \mathrm{~dB} / \mathrm{cm}$, and values up to $3 \mathrm{~dB} / \mathrm{cm}$ will have a significant margin of error. However, for the $\mathrm{KY}\left(\mathrm{WO}_{4}\right)_{2}$ crystals used, this is the only method available to measure transmission losses.

\section{RESULTS}

The bulk transmission spectra of the irradiated crystal for several annealing temperatures are shown in Figure 2, with the spectrum of an unirradiated sample as reference. The graph indicates a significant reduction of transmission for the visible spectrum due to the ion irradiation. This effect can be caused by both the formation of color centers in the material and the added presence of carbon. Annealing of the sample leads to a partial recovery of the transmission spectrum, but remaining (and possibly permanent) color centers and the presence of carbon ions prevent full recovery to the virgin crystal spectrum. For the visible spectrum, the irradiation has a negative effect on the transmissivity of the material, which can have implications for the use of the produced slab waveguides for visible wavelengths. However, for wavelengths of $650-750 \mathrm{~nm}$ the transmissivity is not significantly reduced by the ion irradiation, and for even higher wavelengths both color centers and carbon absorption do not affect the transmission properties of the material. 


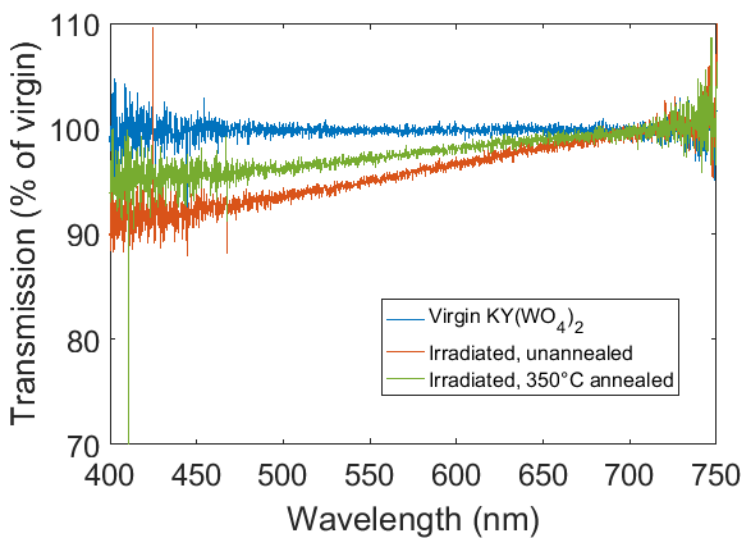

Figure 2. Transmission spectrum of bulk crystal as a function of annealing temperature, with the light propagating perpendicular to the slab waveguide plane.

The refractive index profile measured with microreflectivity of an irradiated sample is shown in Figure 3a. This measurement was taken directly after end-facet polishing, implying that the sample was already heated to $100^{\circ} \mathrm{C}$ during the sample mounting process. Due to the limited spatial resolution $(\sim 300 \mathrm{~nm})$, no differences could be observed between the profiles for several annealing temperatures. The electronic and nuclear damage regions can both be observed, and the locations agree with the SRIM results. A thin layer of $\sim 1.5 \mu \mathrm{m}$ at the surface has a refractive index close to unirradiated $\mathrm{KY}\left(\mathrm{WO}_{4}\right)_{2}$ and is separated from the bulk crystal by a lower-index layer, and as a result this surface layer can be used as a slab waveguide. Several fluctuations in the graph have been marked by a red circle, because they are unexpected in the profile. The appearance of these peaks was consistent for several measured locations on the sample. A likely explanation for these fluctuations is the effect of the mechanical polishing on the material. The damaged material, having a lower density, polishes faster, as can be seen in Figure $3 \mathrm{~b}$. The height differences could cause a slight change in direction of the reflected beam resulting in reflected intensity fluctuations that can explain the refractive index fluctuations marked with numbers 1-3. The created trench can cause accumulation of polishing particles at the interfaces between the amorphous region and the crystalline region, which locally increases the polishing speed. This effect can never be completely removed. Additionally, opto-elastic effects could be present in the sample because the amorphous material has a lower density than the surrounding material, thus creating a higher density layer around itself. This could especially affect the fluctuations deeper than the damage layer (marks 3 and 4), where fluctuation 3 is most likely a combination of both effects mentioned.

a)

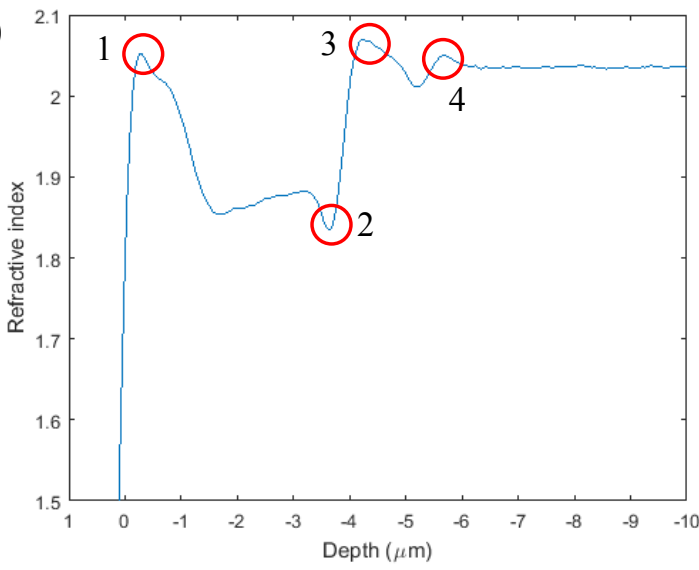

b)
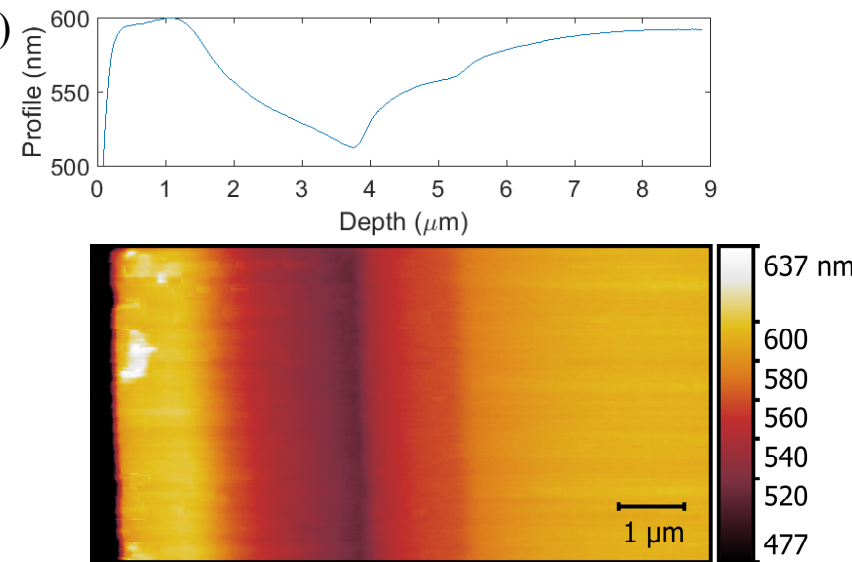

Figure 3. a) Refractive index profile for TE polarized light propagating in the c-direction, caused by ion irradiation of the $K Y\left(W O_{4}\right)_{2}$ crystal. The profile is measured using a micro-reflectivity principle. Several unexpected features in the profile have been marked. $b$ ) Atomic force microscope image scan and extracted height profile of the polished end-facet. Both rounding effects and faster polishing of the damage layer are evident. 
The propagation constants for the fundamental mode of the slab waveguide at several wavelengths are shown in Figure 4a, for polarization along all three crystalline axes. Results are shown for the crystal directly after end-facet polishing, and after annealing at $350^{\circ} \mathrm{C}$. Although the effective refractive index consistently increases slightly with annealing temperature for all polarizations, the changes are very small. No changes are observed for higher temperatures of $400^{\circ} \mathrm{C}$ and $425^{\circ} \mathrm{C}$, so these results were omitted. The slab waveguide supports multiple guided modes for all four wavelengths, as shown in Figure 4b. However, for the future goal of making strip waveguides, the geometry of the strip waveguide will make the structure single mode for the higher wavelengths $(1300$ and $1500 \mathrm{~nm})$. Several Fabry-Perot resonances have also been observed using the prism coupling method, which correspond to substrate modes and give an approximation of the refractive index of the barrier material. The refractive index profile measured using microreflectivity has been used to calculate the effective refractive indices of the slab waveguide using Lumerical MODE Solutions. The mode effective indices calculated from the microreflectivity profile were then compared to the ones measured using the prism coupler method. Figure $4 \mathrm{~b}$ shows a good agreement, especially for the first four modes. Any discrepancies are most likely caused by the inaccuracy in the refractive index profile due to the limited spatial resolution and the artifacts in the measurements discussed above.
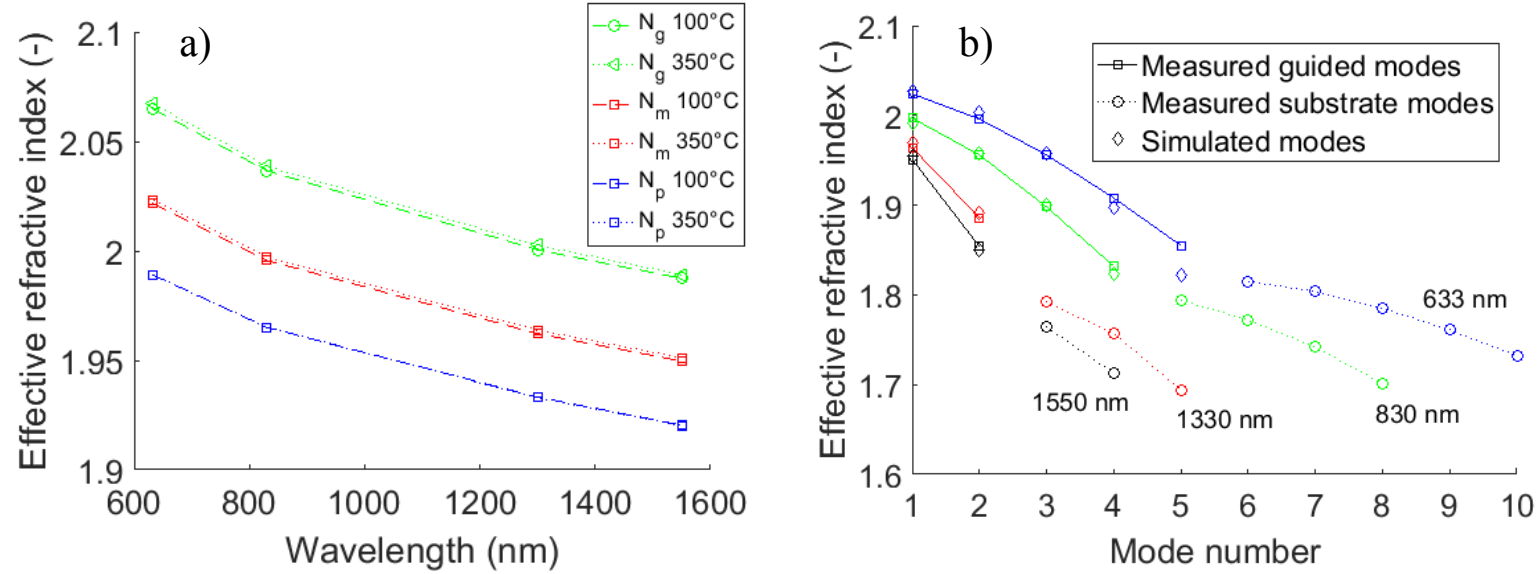

Figure 4. a) Dispersion graph for polarization along all three optical axes of the irradiated $\mathrm{K} Y\left(\mathrm{WO}_{4}\right)_{2}$, for four different wavelengths and two annealing temperatures. The lines connecting the measured data points are for guidance only, and the error in the measurements is much smaller than the symbols; b) the effective refractive index of all guided and substrate modes for polarization along the $N_{m}$ optical axis. The modes for four different wavelengths, are shown, together with the results of mode simulations from the refractive index profile obtained by microreflectivity.

a)

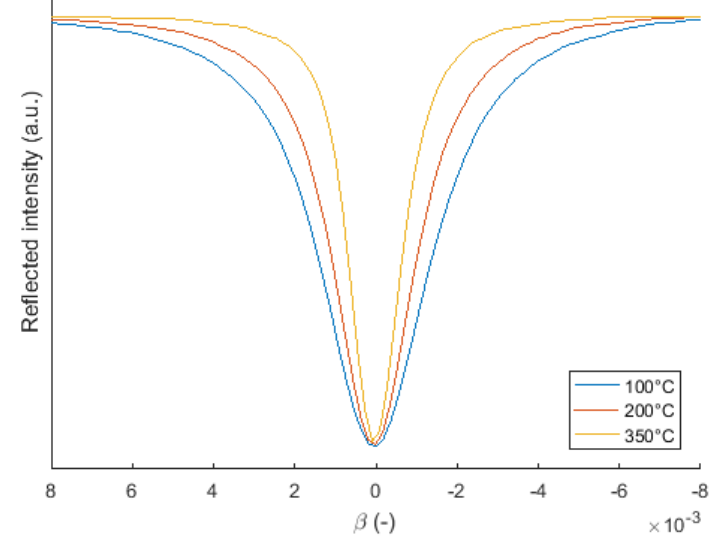

b)

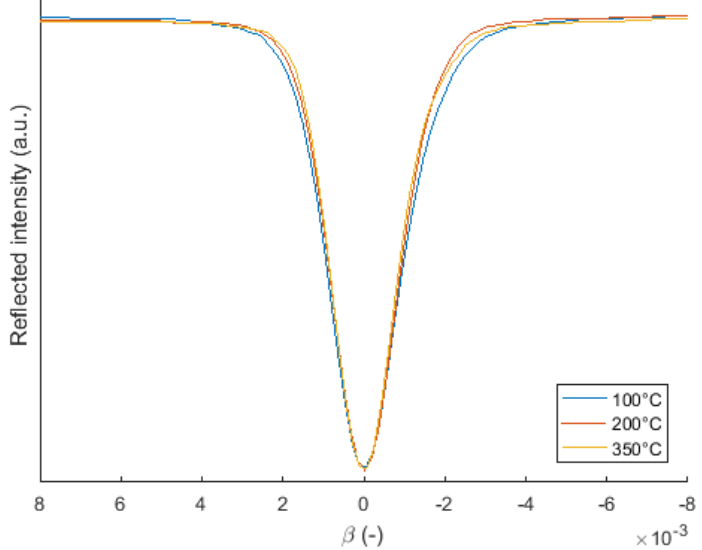

Figure 5. Prism coupling reflection intensity of the fundamental mode as function of the propagation constant relative to the central effective refractive index of the mode, for a wavelength of a) $632.8 \mathrm{~nm}$ and b) $1550 \mathrm{~nm}$, in TE polarization with propagation along the c-axis. 
The prism coupling measurements also give a qualitative indication of the transmission loss of a mode, as broadening of the acceptance angle (hence, a less defined propagation constant) indicates higher losses [28]. Figure 5 shows the profile of the propagation constant of the fundamental TE mode (propagation along the $\mathrm{N}_{\mathrm{g}}$ optical axis, with polarization along the $\mathrm{N}_{\mathrm{m}}$ optical axis) for two wavelengths at several temperatures. It can be observed that the broadening at lower wavelengths is generally higher. This is caused by the dominant scattering effect due to ion damage, which is proportional to $\frac{1}{\lambda^{4}}$. It can additionally be affected by the reduction in transmissivity (Figure 2) caused by color center formation. Increasing annealing temperature significantly reduces the amount of scattering points in the irradiated crystal, leading to reduced optical losses. The initial optical loss is much smaller for longer wavelengths, and subsequently the loss reduction after annealing is also smaller.

The transmission losses of the waveguides were determined for a wavelength of $1550 \mathrm{~nm}$. Figure 6 shows the results for two different samples. Loss calculation has been done only for the region indicated by the yellow squares (Figure 6a,c), because several reflections from the crystal bottom and end-facet make it impossible to use a larger area. The intensity graphs (Figure 6b,d) and subsequent exponential fit indicate a loss around $1.5 \mathrm{~dB} / \mathrm{cm}$. However, it should be noted that for this measurement method, the error margin is very large for short waveguides. Additionally, it is uncertain whether all light from the reflections is really excluded. If this is not the case, the transmission loss could be significantly lower, as the intensity of the reflected light will also decay along the propagation direction.
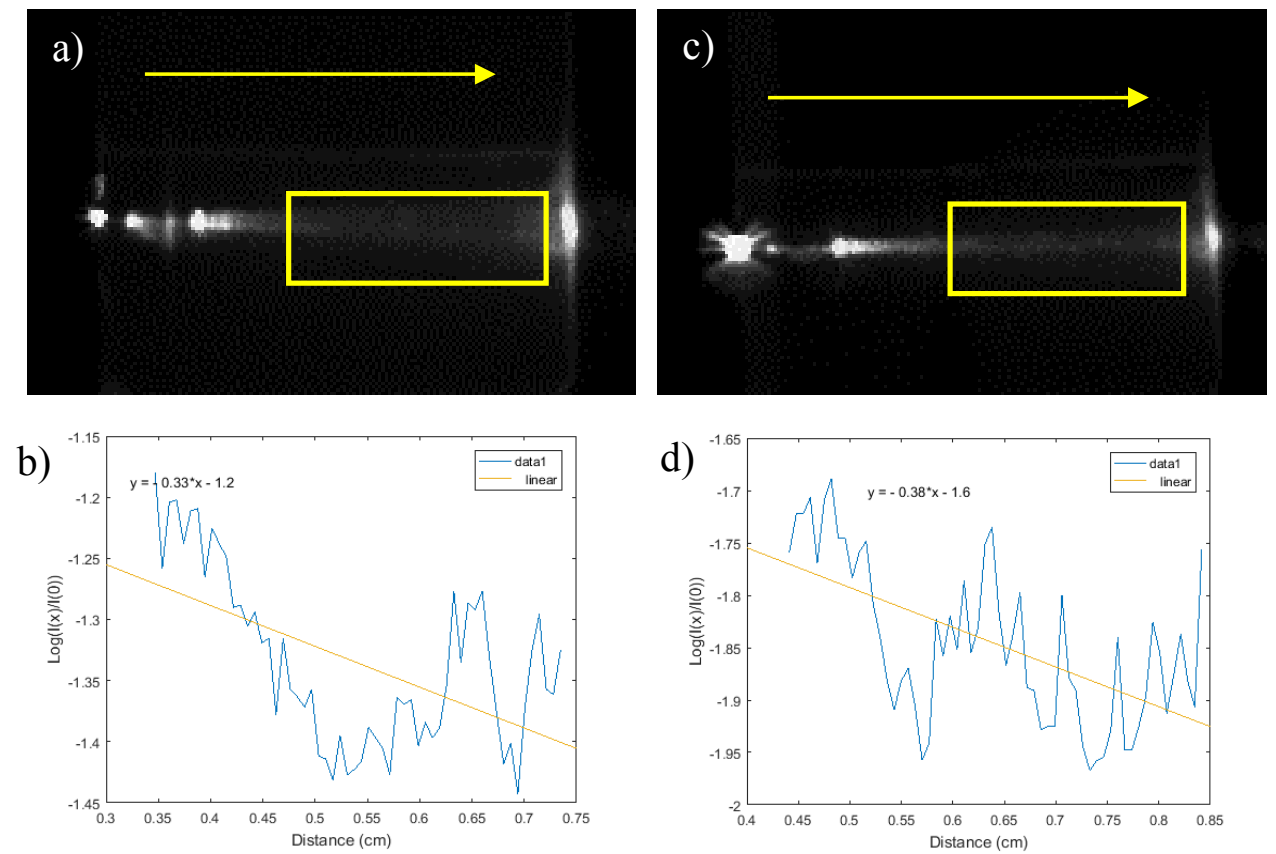

Figure 6. a,c) Camera image of the scattering loss for two different waveguides at a wavelength of $1550 \mathrm{~nm}$. The arrow indicates the propagation along the c-axis with TE polarization. The yellow squares indicate the area used for loss calculation. b,d) Scattered intensity graphs of the areas of interest, plotted on a $\log _{10} y$-axis according to Equation 2. The linear fit is presented for the $\log _{10}$ base, of which the slope value is used together with Equation 3 to calculate the loss in $\mathrm{dB} / \mathrm{cm}$.

\section{CONCLUSIONS}

Fabrication of high index contrast optical waveguides in $\mathrm{KY}\left(\mathrm{WO}_{4}\right)_{2}$ with acceptable losses has been shown for the first time. The refractive index profile has been measured directly using a micro-reflectivity approach, although the relatively low resolution combined with mechanical polishing of the end-facet induces some artefacts in the profile. Direct measurement of the propagation constants of the structure indicates the formation of a close to step-like slab waveguide, and mode calculations using the refractive index profile confirm the measured propagation constants of the guided modes. Finally, optical losses of $\sim 1.5 \mathrm{~dB} / \mathrm{cm}$ have been found for these waveguides, which is lower than the typical gain achieved in rare-earth doped $\mathrm{KY}\left(\mathrm{WO}_{4}\right)_{2}$. The results shown in this work are a very promising starting point for the fabrication of the first high-index contrast channel waveguides in this material. 


\section{ACKNOWLEDGMENTS}

The research leading to these results has received funding from the European Research Council under ERC Consolidator grant RENOS, project number 648978.

\section{REFERENCES}

[1] A. A. Kovalyov, V. V. Preobrazhenskii, M. A. Putyato, O. P. Pchelyakov, N. N. Rubtsova, B. R. Semyagin, V. E. Kisel', S. V. Kuril'chik, and N. V. Kuleshov, "115 fs pulses from $\mathrm{Yb}^{3+}: \mathrm{KY}\left(\mathrm{WO}_{4}\right)_{2}$ laser with low loss nanostructured saturable absorber," Laser Phys. Lett., vol. 8, no. 6, pp. 431-435, Jun. 2011.

[2] U. Griebner, S. Rivier, V. Petrov, M. Zorn, G. Erbert, M. Weyers, X. Mateos, M. Aguiló, J. Massons, and F. Díaz, "Passively mode-locked Yb:KLu($\left(\mathrm{WO}_{4}\right)_{2}$ oscillators," Opt. Express, vol. 13, no. 9, p. 3465, 2005.

[3] A. A. Lagatsky, F. Fusari, S. Calvez, J. a Gupta, V. E. Kisel, N. V Kuleshov, C. T. a Brown, M. D. Dawson, and W. Sibbett, "Passive mode locking of a Tm,Ho:KY $\left(\mathrm{WO}_{4}\right)_{2}$ laser around 2 microm.," Opt. Lett., vol. 34, no. 17, pp. 2587-9, Sep. 2009.

[4] A. Beyertt, D. Nickel, and A. Giesen, "Femtosecond thin-disk Yb:KYW regenerative amplifier," Appl. Phys. B Lasers Opt., vol. 80, no. 6, pp. 655-660, May 2005.

[5] X. Mateos, S. Lamrini, K. Scholle, P. Fuhrberg, S. Vatnik, P. Loiko, I. Vedin, M. Aguiló, F. Díaz, U. Griebner, and V. Petrov, "Holmium thin-disk laser based on Ho:KY $\left(\mathrm{WO}_{4}\right)_{2} / \mathrm{KY}\left(\mathrm{WO}_{4}\right)_{2}$ epitaxy with $60 \%$ slope efficiency and simplified pump geometry," Opt. Lett., vol. 42, no. 17, p. 3490, Sep. 2017.

[6] A. A. Kaminskii, P. V. Klevtsov, L. Li, and A. A. Pavlyuk, "Stimulated emission from $\mathrm{KY}\left(\mathrm{WO}_{4}\right)_{2}: \mathrm{Nd}^{3+}$ crystal laser," Phys. Status Solidi, vol. 5, no. 2, pp. K79-K81, May 1971.

[7] V. Petrov, M. C. Pujol, X. Mateos, Ò. Silvestre, S. Rivier, M. Aguiló, R. M. Solé, J. Liu, U. Griebner, and F. Díaz, "Growth and properties of $\mathrm{KLu}\left(\mathrm{WO}_{4}\right)_{2}$, and novel ytterbium and thulium lasers based on this monoclinic crystalline host," Laser Photonics Rev., vol. 1, no. 2, pp. 179-212, May 2007.

[8] Z. Cong, Z. Liu, Z. Qin, X. Zhang, H. Zhang, J. Li, H. Yu, and W. Wang, "LD-pumped actively Q-switched $\mathrm{Nd}: \mathrm{KLu}\left(\mathrm{WO}_{4}\right)_{2}$ self-Raman laser at 1185nm," Opt. Laser Technol., vol. 73, pp. 50-53, Oct. 2015.

[9] A. A. Kaminskii, A. F. Konstantinova, V. P. Orekhova, A. V Butashin, R. F. Klevtsova, and A. A. Pavlyuk, "Optical and nonlinear laser properties of the $\chi^{(3)}$-active monoclinic $\alpha-\mathrm{KY}\left(\mathrm{WO}_{4}\right)_{2}$ crystals," Crystallogr. Reports, vol. 46, no. 4, pp. 665-672, Jul. 2001.

[10] M. C. Pujol, X. Mateos, R. Sole, J. Massons, J. Gavalda, X. Solans, F. D1'az, and M. Aguilo, "Structure, crystal growth and physical anisotropy of $\mathrm{KYb}\left(\mathrm{WO}_{4}\right)_{2}$, a new laser matrix," J. Appl. Crystal-logr., no. 35, pp. 108-112, 2002.

[11] N. V. Kuleshov, A. A. Lagatsky, V. G. Shcherbitsky, V. P. Mikhailov, E. Heumann, T. Jensen, A. Diening, and G. Huber, "CW laser performance of $\mathrm{Yb}$ and Er,Yb doped tungstates," Appl. Phys. B Lasers Opt., vol. 64, no. 4, pp. 409-413, Mar. 1997.

[12] N. Thilmann, G. Strömqvist, M.-C. Pujol, V. Pasiskevicius, V. Petrov, and F. Díaz, "Nonlinear Refractive Indices in Undoped and $\mathrm{Yb}$-Doped $\mathrm{KT}\left(\mathrm{WO}_{4}\right)_{2} \mathrm{~T}=\mathrm{Y}, \mathrm{Yb}, \mathrm{Gd}$, Lu Crystals," in Conference on Lasers and ElectroOptics/International Quantum Electronics Conference, 2009, p. JWA27.

[13] D. Geskus, S. Aravazhi, S. M. García-Blanco, and M. Pollnau, "Giant optical gain in a rare-earth-ion-doped microstructure," Adv. Mater., vol. 24, no. 10, p. OP19-OP22, Mar. 2012.

[14] D. Geskus, S. Aravazhi, C. Grivas, K. Wörhoff, and M. Pollnau, "Microstructured $\mathrm{KY}\left(\mathrm{WO}_{4}\right)_{2}: \mathrm{Gd}^{3+}, \mathrm{Lu}^{3+}, \mathrm{Yb}^{3+}$ channel waveguide laser," Opt. Express, vol. 18, no. 9, p. 8853, Apr. 2010.

[15] Y. E. Romanyuk, "Liquid-phase epitaxy of doped $\mathrm{KY}\left(\mathrm{WO}_{4}\right)_{2}$ layers for waveguide lasers," École Polytechnique Fédérale de Lausanne, 2005.

[16] M. A. Sefunc, F. Segerink, and S. Garcia-Blanco, "High index contrast potassium double tungstate waveguides towards efficient rare-earth ion amplification on-chip," 2015, vol. 9365, p. 93650P-93650P-6.

[17] F. M. Bain, a a Lagatsky, R. R. Thomson, N. D. Psaila, N. V Kuleshov, a K. Kar, W. Sibbett, and C. T. a Brown, "Ultrafast laser inscribed $\mathrm{Yb}: \mathrm{KGd}\left(\mathrm{WO}_{4}\right)_{2}$ and $\mathrm{Yb}: \mathrm{KY}\left(\mathrm{WO}_{4}\right)_{2}$ channel waveguide lasers.," Opt. Express, vol. 17 , no. 25 , pp. 22417-22422, Dec. 2009.

[18] M. Pollnau, Y. E. Romanyuk, F. Gardillou, C. N. Borca, U. Griebner, S. Rivier, and V. Petrov, "Double tungstate lasers: from bulk toward on-chip integrated waveguide devices," IEEE J. Sel. Top. Quantum Electron., vol. 13, no. 3, pp. 661-671, 2007. 
[19] C. A. Merchant, J. S. Aitchison, S. Garcia-Blanco, C. Hnatovsky, R. S. Taylor, F. Agulló-Rueda, A. J. Kellock, and J. E. E. Baglin, "Direct observation of waveguide formation in $\mathrm{KGd}\left(\mathrm{WO}_{4}\right)_{2}$ by low dose $\mathrm{H}^{+}$ion implantation," Appl. Phys. Lett., vol. 89, no. 11, p. 111116, Sep. 2006.

[20] C. A. Merchant, P. Scrutton, C. Hnatovsky, R. S. Taylor, G. García, J. Olivares, A. S. Helmy, S. Member, and J. S. Aitchison, "High-Resolution Refractive Index and Micro-Raman Spectroscopy of Planar Waveguides in $\mathrm{KGd}\left(\mathrm{WO}_{4}\right)_{2}$ Formed by Swift Heavy Ion Irradiation," IEEE J. Quantum Electron., vol. 45, no. 4, pp. 373-379, 2009.

[21] A. García-Navarro, J. Olivares, G. García, F. Agulló-López, S. García-Blanco, C. Merchant, and J. S. Aitchison, "Fabrication of optical waveguides in KGW by swift heavy ion beam irradiation," Nucl. Instruments Methods Phys. Res. Sect. B Beam Interact. with Mater. Atoms, vol. 249, no. 1-2 SPEC. ISS., pp. 177-180, Aug. 2006.

[22] J. Olivares, G. García, A. García-Navarro, F. Agulló-López, O. Caballero, and A. García-Cabañes, "Generation of high-confinement step-like optical waveguides in $\mathrm{LiNbO}_{3}$ by swift heavy ion-beam irradiation," Appl. Phys. Lett., vol. 86, no. 18, p. 183501, May 2005.

[23] J. Olivares, G. García, F. Agulló-López, F. Agulló-Rueda, A. Kling, and J. C. Soares, "Generation of amorphous surface layers in $\mathrm{LiNbO}_{3}$ by ion-beam irradiation: Thresholding and boundary propagation," Appl. Phys. A Mater. Sci. Process., vol. 81, no. 7, pp. 1465-1469, 2005.

[24] J. F. Ziegler, M. D. Ziegler, and J. P. Biersack, "SRIM - The stopping and range of ions in matter (2010)," Nucl. Instruments Methods Phys. Res. Sect. B Beam Interact. with Mater. Atoms, vol. 268, no. 11-12, pp. 1818-1823, 2010.

[25] C. Jäger, T. Henning, R. Schlögl, and O. Spillecke, "Spectral properties of carbon black," J. Non. Cryst. Solids, vol. 258, no. 1-3, pp. 161-179, Nov. 1999.

[26] S. G. Blanco, J. S. Aitchison, C. Hnatovsky, and R. S. Taylor, "Microreflectivity characterization of the twodimensional refractive index distribution of electron-beam-written optical waveguides in germanium-doped flame-hydrolysis silica," Appl. Phys. Lett., vol. 85, no. 8, pp. 1314-1316, Aug. 2004.

[27] V. Subramaniam, G. N. De Brabander, D. H. Naghski, and J. T. Boyd, "Measurement of mode field profiles and bending and transition losses in curved optical channel waveguides," J. Light. Technol., vol. 15, no. 6, pp. 990997, Jun. 1997.

[28] J. Cardin and D. Leduc, "Determination of refractive index, thickness, and the optical losses of thin films from prism-film coupling measurements," Appl. Opt., vol. 47, no. 7, p. 894, Mar. 2008. 